\title{
AN AUDIT ON PUBLIC AWARENESS OF DEPRESSION SYMPTOMS IN JORDAN
}

\section{SAYER AL-AZZAM ${ }^{1}$, KAREM H. ALZOUBI ${ }^{1}$, NEHAD M. AYOUB ${ }^{1}$, YOUSEF SALEH KHADER ${ }^{2}$, REEMA A. KARASNEH', BELAL A. AL-HUSEIN", and "MOHAMMAD ALI" S. AL-HORANI"}

${ }^{1}$ Jordan University of Science and Technology, Irbid, Jordan

Department of Clinical Pharmacy, Faculty of Pharmacy

${ }^{2}$ Jordan University of Science and Technology, Irbid, Jordan

Department of Public Health, Community Medicine and Family Medicine

${ }^{3}$ Royal Medical Services, Amman, Jordan

\begin{abstract}
Objectives: Depression is a common mental health disorder. The aim of this study is to determine the level of public awareness regarding this illness, its symptoms, associated factors, available forms of treatment, and the attitude towards depressed people. Methods: A self administered questionnaire was filled in by approximately 5000 individuals selected from various regions of Jordan. Results: The majority of participants thought that depression is a treatable condition that can affect patient at any age, and may be controlled by the will power. Loss of interest in things and presence of negative feelings were the most commonly recognized symptoms of depression, while, unemployment and poverty were found to be the most recognized risk factors for depression. In addition, most participants considered support from family and friends (93.6\%) as well as exercise (80.4\%) to be the best available forms of depression treatment. Respondents found it acceptable to work, make friends with, or marry depressed individuals. The first choice persons for seeking help by most participants were family members and friends (49.8\%). Conclusion: Collectively, the level of awareness of depression was acceptable. However, further efforts are necessary to establish public educational programs related to depression in order to raise awareness regarding the disease.
\end{abstract}

Key words:

Awareness, Depression, Jordan, Knowledge, Public attitudes, Risk factors

\section{INTRODUCTION}

Mental illnesses affect approximately one in 5 persons in the United States [1]. Despairing mood and loss of interest or pleasure in nearly all activities previously considered pleasurable are the characteristic features of depression [2]. Due to of the growing recognition of its prevalence, depression has lately received increasing attention [3]. In the United States, depression ranks first among all illnesses that cause disability and occurs two to three times more frequently in women than in men, with a peak incidence during childbearing years [1,3]. In developing countries, depression is documented as a major public health concern. The Global Burden of Disease Study indicated depression to be the single leading cause of Disability Adjusted Life Years by 2020 in the developing world [4].

Many people with depression suffer from it without being diagnosed or treated. Diagnosis of a major depression is

Received: October 9, 2012. Accepted: July 16, 2013.

Corresponding author: S.I. Al-Azzam, Department of Clinical Pharmacy, Faculty of Pharmacy, Jordan University of Science and Technology, P.O. Box 3030 , Irbid 22110 Jordan (e-mail: sayerazzam@yahoo.com). 
based on standard clinical criteria that include depressed mood or loss of interest (or both) for at least 2 weeks, along with a minimum of three up to four out of seven other features that are sufficient to cause clinically important psychological or physical distress or functional impairment. These features include insomnia or hypersomnia, fatigue or loss of energy, diminished thinking or concentration, substantial change in weight or appetite, psychomotor agitation or retardation, and recurrent thoughts of death and suicide $[5,6]$. Given the empirical link between suicide and depression, lack of effective treatment can potentially have fatal consequences [7]. Antidepressant medications and structural psychotherapy are effective forms of treatment for major depression [6]. Many medications, such as tricyclic antidepressants (TCAs), selective serotonin reuptake inhibitors (SSRIs), and serotonin norepinephrine reuptake inhibitors (SNRIs), are available [2]. In addition, a number of complementary and alternative medicine (CAM) and self-help forms of treatment for depression have some supporting evidence of use in adults [8]. Some systematic reviews suggest that for the short-term treatment of depression that is mild or moderate, the herbal remedy St. John's wort (Hypericum perforatum) is more efficacious than placebo [9].

Public awareness is a key element in the management of depression [reviewed in 10]. Public awareness campaign has contributed to the improvement of public knowledge and attitudes, and to reduction of stigma towards depression [11-15]. Almost every person, during their lifetime, will have direct contact with a mental disorder patient [16]. Thus, knowledge about mental disorders is necessary as it directly affects a person's approach and behavior towards those patients [17]. In this study, we assessed the degree of public awareness regarding major depression, its associated symptoms, contributing factors, believes and attitudes towards depressed patients, as well as available treatment options. This assessment was carried out among public in Jordan.

\section{METHODS}

In this study, participants were approached in their workplaces, at classes or at homes. A snowball sampling technique was used in order to collect data i.e. researchers asked every participant to nominate 2 other persons until the desired sample size was obtained. This yielded a sample that is similar in structure to that of the society in Jordan including male to female ratio, and demographic distribution of the population among urban, suburban and rural communities according to data from the Jordanian department of statistics [18].

The study was conducted in various regions of Jordan during the period from October 2007 until February 2008. The questionnaire was distributed, in person, by the researchers. Each participant was provided with a full explanation of the study and instructions how to complete the questionnaire. The respondents were informed that the researcher would be available for any required assistance during scoring of the questionnaire. For a small group of participants who were illiterate, the questionnaire was administered by the researcher in a form of an interview. The completed questionnaires were collected by the researchers and checked to ensure full completion. Confidentiality was maintained as no names or addresses of the respondents were required. Before filling in the questionnaire, the investigator informed all participants that there is no financial reward for their participation. The study protocol was carried out in accordance with the principles described in the Declaration of Helsinki of 1975, including all amendments and revisions. Collected data was accessible only for the investigators. Items of the questionnaire were a modified form of the study of Highet et al. [19]. In its first part, the questionnaire gathered information that included participants' demographic data such as age, gender, nationality, social status, monthly income, place of residence, occupation and level of education. The following parts of the questionnaire assessed knowledge of the patients about symptoms of major depression, factors that 
contribute to the occurrence of depression, best person to seek in case of a developed episode of major depression, and different measures applied in the management of the disorder. The respondents were asked to describe their individual attitudes towards depressed patients.

For these sections, the respondents were given description of the factors, and were asked to provide their responses choosing one from the following answer choices: 1 - Agree and 2 - Disagree, or 1 - Useful and 2 - Not useful. Finally, the respondents were asked to point one person whom they consider as the first choice person for seeking help in case of depressive symptoms. Every person that was eighteen years old was allowed to complete the survey. The questionnaire is available on request (salazzam@just.edu.jo).

Before starting the actual study the questionnaire was piloted. At first, face validity was checked - the questionnaire draft was passed through several colleagues. These colleagues were asked for their opinions about the clarity and correctness of the questions. Then the questionnaire was modified taking into consideration their collective suggestions. Thereafter, to ensure that the respondents would understand what was required from the questions, the questionnaire was further validated using verbal protocols, where 10 individuals were recruited individually and asked to fill in the questionnaire. At the same time, they were asked and encouraged to think loudly, and to speak out about what they meant by each answer, and how they understood each question. The investigator was noting down all their responses, and the questionnaire was adjusted accordingly.

To establish test-retest reliability, 15 subjects were selected randomly, and answered the questionnaire twice with a one-week interval. Test-retest data on each item was analyzed using interclass correlation. For each item, correlation coefficients ranged from $0.75-0.81$, suggesting that the questionnaire is reliable.

The obtained data was analyzed using the SPSS (Statistical Package for the Social Sciences, version 15.0, SPSS Inc.,
Chicago, IL, USA). Frequency analysis of responses was carried out, and the results were tabulated, and compared using the chi-square goodness-of-fit test. For all statistical analyses, the significance level was set at $\mathrm{p}<0.05$.

\section{RESULTS}

This study sample included a total of 5030 adults with a response rate of $97 \%$. Non-respondents were excluded from the total number yielding a total of 4884 participants (male vs. female ratio of 47:53). Demographic data is illustrated in Table 1.

\section{Knowledge about depression}

As regards their knowledge about depression, $81 \%$ of the respondents agree with the fact that depression can affect anyone at any age. However, a small percentage of participants (10\%) agree that depression runs in families. Majority of the participants (88.1\%) agree that depression is a treatable illness. In addition, female gender was correlated with significantly better knowledge concerning the following facts depression may affect anyone at any age, and that it runs in families $(\mathrm{p}<0.05$, Table 2$)$.

\section{Knowledge about symptoms of depression}

Table 3 shows the degree of public awareness regarding symptoms of depression. High percentage of respondents agree that loss of interest in daily activities and the presence of negative feelings are some of the symptoms associated with depression ( 84.4 and $81.3 \%$, respectively). On the other hand, only $36.3 \%$ of the participants believe that drug abuse may be associated with depression. Noteworthy is the fact that female participants had significantly better knowledge about most of the symptoms of the disorder (Table 3 ).

\section{Knowledge about factors contributing to depression}

Public response towards factors contributing to depression is listed in Table 4. Unemployment was considered 
Table 1. Demographic characteristics of the participants

\begin{tabular}{|c|c|c|}
\hline \multirow{2}{*}{ Factor } & \multicolumn{2}{|c|}{ Respondents } \\
\hline & $\mathrm{n}$ & $\%$ \\
\hline \multicolumn{3}{|l|}{ Age (years) } \\
\hline $18-30$ & 3780 & 77.396 \\
\hline $31-40$ & 493 & 10.094 \\
\hline $41-50$ & 371 & 7.596 \\
\hline$>50$ & 239 & 4.894 \\
\hline \multicolumn{3}{|l|}{ Gender } \\
\hline male & 2290 & 46.897 \\
\hline female & 2593 & 53.103 \\
\hline \multicolumn{3}{|l|}{ Nationality } \\
\hline Jordanian & 4011 & 82.142 \\
\hline non-Jordanian & 871 & 17.837 \\
\hline \multicolumn{3}{|l|}{ Social Status } \\
\hline single & 3487 & 71.411 \\
\hline married & 1302 & 26.664 \\
\hline divorced/widowed & 91 & 1.884 \\
\hline \multicolumn{3}{|l|}{ Level of education } \\
\hline illiterate & 50 & 1.024 \\
\hline primary & 115 & 2.356 \\
\hline secondary & 1603 & 32.835 \\
\hline bachelor degree & 2318 & 47.481 \\
\hline postgraduate & 295 & 6.043 \\
\hline \multicolumn{3}{|l|}{ Occupation } \\
\hline medical (e.g. physician, pharmacist, nurse, medical technicians) & 371 & 7.599 \\
\hline teacher & 408 & 8.357 \\
\hline engineer & 320 & 6.555 \\
\hline student & 2382 & 48.791 \\
\hline other jobs (e.g. administrative, dealer, verbatim, farmer, laborer) & 949 & 19.459 \\
\hline housewife & 367 & 7.517 \\
\hline unemployed & 85 & 1.741 \\
\hline \multicolumn{3}{|l|}{ Monthly income of the family (Jordan Dinars) } \\
\hline$<250$ & 1004 & 20.620 \\
\hline $250-500$ & 1637 & 33.621 \\
\hline$>500$ & 2228 & 45.759 \\
\hline \multicolumn{3}{|l|}{ Place of residence } \\
\hline city & 3930 & 80.533 \\
\hline village & 950 & 19.467 \\
\hline
\end{tabular}


Table 2. General awareness concerning depression

\begin{tabular}{lccrr}
\hline \multirow{2}{*}{ Item } & \multicolumn{3}{c}{ Respondents } \\
& \multicolumn{3}{c}{$\mathrm{n}(\%)$} & \multirow{2}{*}{$\mathrm{p}$} \\
\cline { 2 - 4 } & total & male & female & \\
\hline Depression is a treatable illness & $4301(88.1)$ & $2018(88.1)$ & $2283(88.0)$ & 0.933 \\
Depression can be controlled by the willpower & $4086(83.7)$ & $1895(82.8)$ & $2191(84.5)$ & 0.100 \\
Depression may affect anyone at any age & $3956(81.0)$ & $1802(78.7)$ & $2154(83.1)$ & $<0.005$ \\
Causes of depression are well known scientifically & $1860(38.1)$ & $870(38.0)$ & $990(38.2)$ & 0.892 \\
Depression runs in families & $487(10.0)$ & $204(8.9)$ & $283(10.9)$ & 0.020 \\
\hline
\end{tabular}

Table 3. Participants' knowledge about depression symptoms according to gender

\begin{tabular}{|c|c|c|c|c|}
\hline \multirow{2}{*}{$\begin{array}{l}\text { Symptoms } \\
\text { Item }\end{array}$} & \multicolumn{3}{|c|}{$\begin{array}{c}\text { Respondents } \\
\mathrm{n}(\%)\end{array}$} & \multirow[t]{2}{*}{$\mathrm{p}$} \\
\hline & total & male & female & \\
\hline Loss of interest in things & $4119(84.4)$ & $1842(80.4)$ & $2277(87.8)$ & $<0.005$ \\
\hline Presence of negative feelings & $3971(81.3)$ & $1797(78.5)$ & $2174(83.8)$ & $<0.005$ \\
\hline Severe sadness & $3722(76.2)$ & $1645(71.8)$ & $2077(80.1)$ & $<0.005$ \\
\hline A change in behavior & $3772(77.2)$ & $1724(75.3)$ & $2048(79.0)$ & 0.002 \\
\hline Abuse of drugs or substance & $1772(36.3)$ & $859(37.5)$ & $913(35.2)$ & 0.095 \\
\hline
\end{tabular}

a contributing factor to the development of depression by majority of the respondents $(73.4 \%)$. In comparison, only a small percentage of respondents (12.7\%) considered marriage as a significant contributing factor to the development of the disease. Significantly higher percentage of females considered poverty, drug abuse, divorce, and envy or magic as contributing factors to depression. On the other hand, a significantly higher percentage of males considered disease states as a contributing factor to depression.

Table 4. Awareness of risk factors related to the development of depression

\begin{tabular}{|c|c|c|c|c|}
\hline \multirow[t]{2}{*}{ Associated factors } & \multicolumn{3}{|c|}{$\begin{array}{c}\text { Respondents } \\
\mathrm{n}(\%)\end{array}$} & \multirow{2}{*}{$\mathrm{p}$} \\
\hline & total & male & female & \\
\hline Unemployment & $3583(73.4)$ & $1653(72.2)$ & $1930(74.4)$ & 0.076 \\
\hline Poverty & $3172(65.0)$ & $1452(63.4)$ & $1720(66.3)$ & 0.032 \\
\hline Drugs or alcohol misuse & $2444(50.1)$ & $1107(48.3)$ & 1337 (51.6) & 0.025 \\
\hline Divorce & $2125(43.5)$ & $819(35.8)$ & $1306(50.4)$ & $<0.005$ \\
\hline Heavy work & $1547(31.7)$ & $736(32.1)$ & $811(31.3)$ & 0.518 \\
\hline Envy or magic & $1444(29.6)$ & $607(26.5)$ & $837(32.3)$ & $<0.005$ \\
\hline Severe Disease & $958(19.6)$ & $501(21.9)$ & $457(17.6)$ & $<0.005$ \\
\hline Marriage & $619(12.7)$ & $302(13.2)$ & $317(12.2)$ & 0.313 \\
\hline
\end{tabular}




\section{Rating of treatment options available for depression}

When asked about the likely effects of various treatment approaches for the management of depression, majority of the respondents reported that support from family and friends, exercise, as well as the use of antidepressants were useful (Table 5). Females recognized natural herbs, vitamins and minerals, analgesics, and antidepressants as useful treatment options for depression (Table 5).

\section{Attitudes towards depressed individuals}

Public attitude towards depressed patients was assessed according to the gender (Table 6). Majority of the respondents $(75.5 \%)$ agreed that they can work with a depressed person. While minority of participants $(4.4 \%)$ agreed that depressed individuals have mental retardation (Table 6).

\section{First choice person for seeking help} in case of depressive symptoms

The responses to the question "If you feel depressed, who do you first refer to?" are shown in Table 7. About half of the participants (49.8\%) recognized friends and family members as the first choice persons to seek help. On the contrary, seeking help from a psychologist was among the least frequently chosen options (2.4\%, respectively). The reminder of responses included other options such as: a general practitioner, a psychiatrist, a pharmacist, and others.

Table 5. Rating of available treatments for depression

\begin{tabular}{|c|c|c|c|c|}
\hline \multirow{2}{*}{ Method } & \multicolumn{3}{|c|}{$\begin{array}{l}\text { Respondents } \\
\mathrm{n}(\%)\end{array}$} & \multirow{2}{*}{$\mathrm{p}$} \\
\hline & total & male & female & \\
\hline Support from family \& friends & $4570(93.6)$ & $2139(93.4)$ & $2431(93.8)$ & 0.622 \\
\hline Exercise & $3927(80.4)$ & $1830(79.9)$ & $2097(80.9)$ & 0.399 \\
\hline Antidepressants & $2907(59.5)$ & $1311(57.2)$ & $1596(61.6)$ & 0.002 \\
\hline Vitamins \& minerals & $1696(34.7)$ & $680(29.7)$ & $1016(39.2)$ & $<0.005$ \\
\hline Natural herbs & $1366(28.0)$ & $572(25.0)$ & $794(30.6)$ & $<0.005$ \\
\hline Sedatives and hypnotics & $1272(26.0)$ & $614(26.8)$ & $658(25.4)$ & 0.254 \\
\hline Analgesics & $828(17.0)$ & $361(15.8)$ & $467(18.0)$ & 0.037 \\
\hline
\end{tabular}

Table 6. Public attitude towards depressed patients according to the gender

\begin{tabular}{|c|c|c|c|c|}
\hline \multirow[t]{2}{*}{ Item } & \multicolumn{3}{|c|}{$\begin{array}{l}\text { Respondents } \\
\mathrm{n}(\%)\end{array}$} & \multirow{2}{*}{$\mathrm{p}$} \\
\hline & total & male & female & \\
\hline I am willing to work with them & $3685(75.5)$ & $1665(72.7)$ & $2020(77.9)$ & $<0.005$ \\
\hline I am willing to make friends with them & $3675(75.3)$ & $1705(74.5)$ & $1970(76.0)$ & 0.219 \\
\hline I am willing to marry one with depression & $2049(42.0)$ & $932(40.7)$ & $1117(43.1)$ & 0.093 \\
\hline They are mentally retarded & $215(4.4)$ & $129(5.6)$ & $86(3.3)$ & $<0.005$ \\
\hline
\end{tabular}


Table 7. First choice person for seeking help in case of depressive symptoms development

\begin{tabular}{lrrrr}
\hline \multirow{2}{*}{\multicolumn{1}{c}{ Person }} & \multicolumn{3}{c}{ Respondents } \\
n $(\%)$ & \multirow{2}{c}{$p$} \\
\cline { 2 - 3 } & \multicolumn{1}{c}{ total } & male & female & 0.190 \\
\hline Family and friends & $2432(49.8)$ & $1161(50.7)$ & $1271(49.0)$ & \\
Psychiatrist & $1172(24.0)$ & $539(23.5)$ & $633(24.4)$ & \\
Self-help & $676(13.8)$ & $300(13.1)$ & $376(14.5)$ & \\
Psychologist & $115(2.4)$ & $51(2.2)$ & $64(2.5)$ & \\
General practitioner & $103(2.1)$ & $59(2.6)$ & $44(1.7)$ & \\
Pharmacist & $13(0.3)$ & $8(0.3)$ & $5(0.2)$ & \\
\hline
\end{tabular}

\section{DISCUSSION}

This study indicated acceptable public awareness of major depression, its symptoms, contributing factors, available treatment options, and attitudes towards depressed patients. Generally, the female respondents showed significantly higher degree of awareness of depression compared to the male respondents. This correlates with the findings of a previous study on Australian population which show that females were more likely to correctly identify symptoms of depression than males [20,21]. Additionally, a number of studies showed that females were more aware of symptoms of mental illnesses than males, and were less likely to delay seeking help for such illnesses [22,23].

Majority of the respondents in this study expressed a view that unemployment results in depressive disorders. In fact, affective disorders have a multifactorial etiology, where biological, psychological, and sociological factors may be of importance in the case of the onset as well as in the case of relapses of such disorders [24]. According to our results, unemployment and depression were shown to be interrelated and problematic at both individual and societal levels [25]. Additionally, studies showed that low socioeconomic status is a risk factor for depression [25-27]. Poverty and substance abuse are other most commonly endorsed causes of depression are. Similarly to our findings, an Australian study results showed that unemployment, or having a serious medical condition are factors associated with depression [19].

Moreover, being married or in a relationship (which is a known protective factor) was thought to be a risk factor for depression by more than a half $(55 \%)$ of the Australian sample [19]. In our study, only $12.7 \%$ thought that marriage is a contributing factor for depression. Having a job with lots of responsibilities was rated as a risk factor by $67 \%$ of the respondents in Australia compared to $31.7 \%$ of Jordanians in this study. On the contrary, the results of a community study of the knowledge and attitude towards mental illness in Nigeria showed that most respondents considered substance abuse as a leading cause of mental illness, followed by the belief that mental illness could be due to possession by evil spirits [28]. These differences in people's believes could be a result of different cultural, social, economic or religious backgrounds among different populations in the world.

Although several treatment methods are available for mental disorders, many patients still receive no optimal or no professional help. This can be attributed to various factors including individual believes about various types of professional help being available or not. A predominantly negative attitude towards psychotropic medications was reported and could be attributed to concerns about side effects, and the belief that medications only deal with the symptoms rather than cure [29]. When asked to identify 
their first choice treatment for depression, the participants of this study rated family support and exercise as the top helpful measures for depression. Antidepressants, vitamins and minerals, and natural herbs came next. This correlates with the results of the previous studies [e.g. 19]. Generally, public attitudes towards mental patients and psychiatric treatments are unfavorable [30]. Negative attitudes towards depression are one of the reasons for underestimation of depressive disorders in the community and clinical settings [31]. Most respondents in this survey displayed positive attitude towards depressed patients. The highest percentage of participants agreed to work with depressed patients, befriending them and marrying one with depression. Again, females showed more positive attitude towards people with depression compared to the male participants. In accordance with that, a recent report on a large sample of Turkish university students showed that the female respondents had less stigmatizing attitude towards the mentally ill individuals than the male respondents [32]. This could be related to females' comparatively optimistic opinions about treatability of mental illnesses.

However, a study from Nigeria reported generally negative views about mental illnesses among public. In that population, patients with mental illness were believed to be mentally retarded. In addition, most Nigerian respondents were unwilling to have social interactions with someone with a mental illness. Furthermore, most respondents prefered to avoid conversations and would feel disturbed to work with a person suffering from a mental illness. Only a few would be willing to maintain a friendship and even fewer would consider marrying such a person [28]. Similar responses were detected in a Pakistani survey about the attitude of university students and teachers towards mentally ill people with schizophrenia, depression, and drug or alcohol disorders [33].

Participants of this study showed a strong reliance on family and friends as the first choice persons for seeking help in case of depressive symptoms. Professional therapists were the second common choice, while GPs and pharmacists ranked later. In comparison with the results reported in the Australian study, majority of the respondents selected GPs as the first choice persons to seek help, followed by family and friends, psychiatrists, and finally psychologists [34]. This difference could be due to cultural issues related to strong family support and commitments in the Jordanian society. Remarkably, results of this study and the Australian one [19] showed greater role of family members and friends compared to health care specialists for patients seeking medical help for depression in our society.

The results of this study indicate the need for raising awareness programs for the institutions and specialists providing professional help in case of occurrence of depressive symptoms. In addition, educational programs should be developed, and implemented in order to educate public in the field of depression symptoms. Such programs have been shown to improve public awareness, attitude, and reduce stigma towards depression symptoms, and its treatment options [11-15].

Limitations of this study include the fact that the participants had to complete the surveys in the presence of the researcher who also answered all the questionnaire-related questions raised by the participants. While this could imply some sort of change in participants' behavior because they could have felt being watched by the researcher, it was also necessary to ensure that participants would fully complete, and return the questionnaire forms. A significant percentage of the participants had at least university education, and were either students or specialists. Thus, such a sample could show higher level of awareness of depression than other sectors of the society that are less educated or work in simple or non-specialized jobs.

In conclusion, Jordanian population has acceptable level of awareness and a generally positive attitude towards depressed individuals. Females have better knowledge about depression than males. Nevertheless, efforts are needed for more public education in the field of depression in its different facets through health-related programs that are directed to the general public. 


\section{REFERENCES}

1. Sanders LB. Attitudes, perceived ability, and knowledge about depression screening: A survey of certified nurse-midwives/certified midwives. J Midwifery Womens. Health 2006;51(5):340-6.

2. To SE, Zepf RA, Woods AG. The symptoms, neurobiology, and current pharmacological treatment of depression. J Neurosci Nurs. 2005;37(2):102-7.

3. Merry SN. Prevention and early intervention for depression in young people - A practical possibility? Curr Opin Psychiatry. 2007;20(4):325-9.

4. Taqui AM, Itrat A, Qidwai W, Qadri Z. Depression in the elderly: Does family system play a role? A cross-sectional study. BMC Psychiatry. 2007;7:57.

5. Mann JJ. The medical management of depression. N Engl J Med. 2005;353(17):1819-34.

6. Whooley MA, Simon GE. Managing depression in medical outpatients. N Engl J Med. 2000;343(26):1942-50.

7. Patel VL, Branch T, Mottur-Pilson C, Pinard G. Public awareness about depression: The effectiveness of a patient guideline. Int J Psychiatry Med. 2004;34(1):1-20.

8. Jorm AF, Allen NB, O'Donnell CP, Parslow RA, Purcell R, Morgan AJ. Effectiveness of complementary and self-help treatments for depression in children and adolescents. Med J Aust. 2006;185(7):368-72.

9. Carpenter DJ. St. John's wort and S-adenosyl methionine as "natural" alternatives to conventional antidepressants in the era of the suicidality boxed warning: What is the evidence for clinically relevant benefit? Altern Med Rev. 2011;16(1): 17-39.

10. Gargiulo A, Ebmeier KP. Awareness key in managing depression in later life. Practitioner. 2008;252(1705):32,34,37 (passim).

11. Jones AR, Cook TM, Wang J. Rural-urban differences in stigma against depression and agreement with health professionals about treatment. J Affect Disord. 2011;134 (1-3):145-50.
12. Cook TM, Wang J. Descriptive epidemiology of stigma against depression in a general population sample in Alberta. BMC Psychiatry. 2010;10:29.

13. Wang JN, Sun W, Chi TS, Wu H, Wang L. Prevalence and associated factors of depressive symptoms among Chinese doctors: A cross-sectional survey. Int Arch Occup Environ Health. 2010;83(8):905-11.

14. Wang J, Fick G, Adair C, Lai D. Gender specific correlates of stigma toward depression in a Canadian general population sample. J Affect Disord. 2007;103(1-3):91-7.

15. Dumesnil H, Verger P. Public awareness campaigns about depression and suicide: A review. Psychiatr Serv. 2009;60(9):1203-13.

16. Kessler RC, McGonagle KA, Zhao S, Nelson CB, Hughes M, Eshleman S, et al. Lifetime and 12-month prevalence of DSM-III-R psychiatric disorders in the United States. Results from the National Comorbidity Survey. Arch Gen Psychiatry. 1994;51(1):8-19.

17. Jorm AF. Mental health literacy. Public knowledge and beliefs about mental disorders. Br J Psychiatry. 2000;177: 396-401.

18. Department of Statisitcs. Jordan in figures. 2012. 14th ed., Amman: DOS Press; zon, 6-9.

19. Highet NJ, Hickie IB, Davenport TA. Monitoring awareness of and attitudes to depression in Australia. Med J Aust. 2002;176 Suppl:S63-8.

20. Burns JR, Rapee RM. Adolescent mental health literacy: Young people's knowledge of depression and help seeking. J Adolesc. 2006;29(2):225-39.

21. Cotton SM, Wright A, Harris MG, Jorm AF, McGorry PD. Influence of gender on mental health literacy in young Australians. Aust N Z J Psychiatry. 2006;40(9):790-6.

22. Verbrugge LM. Sex differences in complaints and diagnoses. J Behav Med. 1980;3(4):327-55.

23. Verbrugge LM, Wingard DL. Sex differentials in health and mortality. Health Matrix. 1987;5(2):3-19.

24. Johnson L, Andersson-Lundman G, Aberg-Wistedt A, Mathe AA. Age of onset in affective disorder: Its correlation 
with hereditary and psychosocial factors. J Affect Disord. 2000;59(2):139-48.

25. Mascaro N, Arnette NC, Santana MC, Kaslow NJ. Longitudinal relations between employment and depressive symptoms in low-income, suicidal African American women. J Clin Psychol. 2007;63(6):541-53.

26. Bhatia SK, Bhatia SC. Childhood and adolescent depression. Am Fam Physician. 2007;75(1):73-80.

27. Bromberger JT, Harlow S, Avis N, Kravitz HM, Cordal A. Racial/ethnic differences in the prevalence of depressive symptoms among middle-aged women: The Study of Women's Health Across the Nation (SWAN). Am J Public Health. 2004;94(8):1378-85.

28. Gureje O, Lasebikan VO, Ephraim-Oluwanuga O, Olley BO, Kola L. Community study of knowledge of and attitude to mental illness in Nigeria. Br J Psychiatry. 2005;186:436-41.

29. Jorm AF, Nakane $Y$, Christensen H, Yoshioka K, Griffiths KM, Wata Y. Public beliefs about treatment and outcome of mental disorders: A comparison of Australia and Japan. BMC Med. 2005;3:12.

30. Chung KF, Chen EY, Liu CS. University students' attitudes towards mental patients and psychiatric treatment. Int J Soc Psychiatry. 2001;47(2):63-72.

31. Postuvan V, Becaj J, Marusic A. Nurses' attitudes towards depression: a study in Slovenia. Psychiatr Danub 2007;19(1-2):61-7.

32. Savrun BM, Arikan K, Uysal O, Cetin G, Poyraz BC, Aksoy $\mathrm{C}$, et al. Gender effect on attitudes towards the mentally ill: A survey of Turkish university students. Isr J Psychiatry Relat Sci. 2007;44(1):57-61.

33. Javed Z, Naeem F, Kingdon D, Irfan M, Izhar N, Ayub M. Attitude of the university students and teachers towards mentally ill, in Lahore, Pakistan. J Ayub Med Coll Abbottabad. 2006;18(3):55-8.

34. Goldney RD, Fisher LJ, Dal Grande E, Taylor AW. Changes in mental health literacy about depression: South Australia, 1998 to 2004. Med J Aust. 2005;183(3):134-7.

This work is available in Open Access model and licensed under a Creative Commons Attribution-NonCommercial 3.0 Poland License - http://creativecommons.org/ licenses/by-nc/3.0/pl/deed.en. 